\title{
EDUARDO MILÁN
}

\section{Entrevista con Alejandro Rossi}

Alejandro Rossi, uno de los narradores más brillantes de Hispanoamérica, es un escritor bien conocido en México. La siguiente conversación se refiere básicamente a un cuento, Sedosa, la niña, relato que condensa ejemplarmente varias de las procupaciones de este narrador; entre otras: el mecanismo de relojería del relato, la desolación de sus personajes frente a la historia, la pregunta por el sentido de la vida.

Eduardo Milán: Rossi, icómo trabaja usted el lenguaje de un cuento? ¿Trabaja con lenguajes en bloque o trabaja con unidades mínimas? ¿Cómo plantea el lenguaje cuando va a escribir un cuento?

Alejandro Rossi: Bueno, mire Milán, me gusta la expresión unidades mínimas. Yo creo que el gran problema de un cuento, es un lugar común decirlo, es dar con el primer tono. El primer tono es la voz del cuento, es el hilo. Muchas veces el tono proporciona el hilo narrativo más que una anécdota completa. Al menos a mí me ocurre así. Y esto también porque muchas veces cuando escribimos un cuento no lo tenemos todo en la cabeza; a veces tenemos una frase, a veces una idea suelta, a veces, si se es afortunado, el final del cuento, o por dónde va el final. Lo que quiero decir es que es muy difícil tener (al menos en mi caso) todo el relato. Es decir, que yo no me siento a escribir el cuento sabiendo ya cómo empieza, lo que sigue, cómo va a terminar, etc. Por lo general no es así. Por eso los tonos son importantes; son la pequeña brújula que tiene el escritor. La pequeña brájula que lo va orientando un poco. Puede saber una frase de un personaje y, a lo mejor, el cuento se construye alrededor de esa frase, o tal vez conoce una anécdota muy general o quizá algún 
incidente, o muchas veces ni siquiera eso; muchas veces es simplemente una especie de sensación verbal que se parece mucho a una intuición musical, aunque no sea con notas, por supuesto, sino que se tiene una suerte de ruido en la cabeza y uno sabe que por ahí va la cosa. Creo que yo empiezo a escribir un cuento, mejor dicho, continúo un cuento, cuando siento que el tono me ha sido dado y después viene el descubrimiento del cuento. $Y$ hay un momento en la escritura de los cuentos en que ya nos sentimos "seguros", no porque sepamos el final o el desarrollo de lo que sigue, sino porque tenemos ya la brújula del tono. Uno ya sabe en qué tono está escribiendo y entonces hay unas elecciones que se hacen, por así decirlo, de forma natural. El tono va rechazando ciertas cosas y va admitiendo otras. Y en ese momento el cuento empieza -aunque no hay que hacer de esto una fantasmagoría literaria-, empieza a tener una cierta autonomía. Entonces uno descansa un poco, porque la tarea, por pedante que suene, se divide entre usted y el cuento. Entonces la tarea de usted en cierto modo es atenderlo, escucharlo un poco, seguirlo y él va marcando, si está bien ideado, si el cuento pega en el clavo, él va marcando el camino y va aceptando o rechazando ciertas sugerencias. El cuento es el guía. Entonces es un trabajo más repartido. Cuando eso ocurre hay un gran descanso; yo creo que el cincuenta por ciento, si cabe hablar así del cuento, está hecho.

M: Por lo que usted dice, como que se originaría a partir de voces, como una cosa material, ¿no? ... Independientemente de lo conceptual, hay un latido ahí ino es así?

$R:$ Sí, así lo creo y no está mal usar la expresión organismo vivo, porque hay algo de eso. De pronto aquello comienza a tener funciones propias y, es cierto, hay, es, repito, una adivinación de ese organismo vivo que a veces viene de cosas muy casuales y muy secretas que yo resumo en una palabra global que es tono, pero que en rigor, son muchas cosas; puede ser, de pronto, la frase de un personaje, la adivinación de un ambiente material, olores, etc. Entonces a partir de ahí hay algo que lo enamora, algo que lo atrae. Más vale no preguntarse demasiado qué es lo que lo atrae y qué es lo que lo enamora, pero uno siente de inmediato cuando hay una conexión y entonces, si usted tiene suerte, pues arranca a escribir el cuento, y si no tiene suerte, pues no lo escribe. 
M: ¿Sería como estar hablado por el cuento, como situarse en la posición de un transmisor, o es demasiado alargar la mano?

$R:$ No; yo creo que es demasiado alargar la mano. Pero lo que sí me parece claro son las dos cosas que dije: una, el tono como brújula y a partir de un cierto momento, que puede ser la segunda página $o$ puede ser mucho más adelante-y esa es una de las grandes angustias cuando escribimos un cuento-, cuando sentimos que el relato ya se formó de algún modo y está exigiendo, que ya no acepta ciertas frases, ciertos adjetivos, ciertas descripciones, ciertos diálogos, sino que los rechaza. Ese momento es buenísimo porque es cuando ya está ahí.

M: Y a partir de ese momento importaría muchísimo la precisión del lenguaje, el tipo de lenguaje que se utiliza, porque si está el organismo vivo, ¿lo que importaría más es desarrollar la vida de ese organismo o decorarlo?

$R:$ No, yo creo que es más bien la primera; hay que ser muy fiel y las selecciones lingüísticas están tomadas como al alimón, porque el cuento tiene su estilo y su tono y su ritmo. Tiene, sobre todo, su velocidad y esas son las cosas que usted como escritor debe atender realmente. Si no les hace caso, el cuento fracasa totalmente. $E$ insisto en esto de la velocidad, porque en un cuento el tiempo es fundamental y si usted le imprime otros tiempos más veloces o más lentos, o crea ciertas confusiones temporales dentro del propio cuento, se arruina definitivamente.

$M$ : El lenguaje no sería entonces una cuestión exterior, sino una cuestión íntima del cuento.

$R$ : Yo diría que sí, y esto se nota bastante bien cuando corregimos. Por lo general yo practico una escritura que no es que se autocorrija en el momento -porque sería una estupidez decirlo así, como si yo estuviera escribiendo y borrando- sino que es una escritura atenta a esos ritmos, a esos tonos, a esas velocidades, a ese tiempo que el cuento parece exigir. Si yo estoy atento a eso, entonces escribo con un cierto cuidado, lo cual es una forma de corregir y nada tiene que ver con la rapidez o la lentitud: a veces puedo escribir rápido, a veces puedo escribir lento, etc., pero tenemos siempre que estar con el oído muy atento y así muchas veces a la hora de escribir nos damos cuenta de que pifiamos la nota, que esa no es y, entonces, interviene la corrección. Y después, cuando el cuento ya está más o menos 
escrito, a mano, por cierto, primero lo leo y lo corrijo en el manuscrito. Luego lo paso a máquina y al hacerlo lo corrijo de nuevo. Cuando lo tengo transcrito a máquina entero, que es la labor más fastidiosa de todo el proceso, entonces es cuando deveras me meto en el cuento y empiezo a corregirlo en serio. Corregirlo en serio significa revisar si hay problemas de estructura, que algo deba ocurrir antes que otra cosa, etc. A mí me ocurre poco porque voy con mucha calma cuando los escribo, y es difícil, entonces, que cambie un elemento estructural. Las correcciones, por lo general, son correcciones o pequeños agregados para enfatizar esto o lo otro, para expresar más una cosa que otra, y sobre todo, para empezar a eliminar sonidos impuros que puede haber en el cuento y tratar de que no haya letra muerta, de que no haya pedazos muertos, de que no haya pesos indebidos en el cuento. Entonces es un proceso doble, a veces de agregar cosas que son siempre pequeñas, que son acerca de los tonos, algo que puede expresarse mejor, una palabra que falta, un adjetivo ausente, un adverbio, algo así; y luego estar atentos, como un afinador de piano, a esa voz que tiene el cuento, para que salga lo más pura posible. Quiero agregar una cosa. A mí me gusta corregir. Ocuparme de lo que usted llamaba "unidades pequeñas"; me gusta corregir, fijarme en una coma. Le doy peso a una coma. Trato de darle peso a todos los elementos que hay alli. Es decir, no me importa decir, "bueno, el cuento está más o menos escrito, expresé más o menos una idea o una visión". No, pienso que en un cuento, que es una cosa tan limitada y tan cerrada, hay que tener muchísimo cuidado de que toda la orquesta suene, de que las comas tengan su significación, de que las preposiciones tengan su importancia, su significación, etc. Creo que es una de las grandes lecciones que nos ha dado Borges, la de las pequeñas unidades lingüísticas.

M: Así, escribir cuentos sería casi como escribir poesía ...

$R$ : No sé como se escriba poesía.

$M$ : Se escribe por pequeñas unidades. Quisiera preguntarle algo. Esa precisión, todo ese afán de verosimilitud, de encontrar un grado de verdaa en el cuento, ¿tiene que ver en cierta forma con su relación de mirada con el mundo? Porque, sigamos con el hilo anterior, se crea un organismo vivo. El oganismo vivo se genera a partir de un 
tono, ¿y cómo se genera un personaje a partir de ese mismo tono que generó el organismo vivo? Es decir, ya tenemos al organismo ¿y luego?

$R$ : Pero el organismo también son los personajes ...

$M$ : También son los personajes, pero icómo se instalan los personajes dentro de ese organismo? Lo que quiero decir es lo siguiente: aquí no puede existir un personaje maravilloso, no puede haber un personaje que transgreda determinados límites que le impone la realidad misma del lenguaje que origina el tiempo, ¿verdad?

$R:$ A ver si le entendí bien. El personaje también está limitado cuando empieza a vivir, es el momento en que él no puede hacer ciertas cosas y otras sí. Es el momento en que su acción se limita muchísimo. Es cuando ya no es un personaje abierto, cuando ya no es omnipotente, cuando ya no tiene todos los destinos a la mano, sino sólo unas cuantas cosas que debe y puede hacer.

$M$ : Exactamente, porque a donde quiero ir es a la relación que tiene su escritura con la escritura de ese destino histórico oficial. El discurso de los personajes también está limitado por un discurso mayor que sería una especie de discurso del destino o de discurso de la oficialidad.

$\therefore \quad R$ : Lo que pasa es que son dos temas.

$M:$ Sí, son dos temas, pero en algún lado tendrían que estar unidos.

$R$ : Son dos temas. Uno es aquel del que hablábamos antes y, si entiendo bien, es el tema del momento en que el personaje empieza a surgir realmente o empieza a vivir en el cuento, que es, como decíamos, el momento en que no todos los destinos son accesibles, cuando puede hacer ciertas cosas y no otras, el momento de la limitación y, por consiguiente, de la definición de sí mismo. El otro tema, si lo entiendo, se refiere a lo que yo cuento en esos relatos en los que hay un contrapunto constante entre la vida de esos personajes y las versiones que, de esas vidas, daría una supuesta historia oficial. Hay, en efecto, esa tensión permanente entre la vida individual que ellos de alguna manera entienden que tuvieron y la vida oficial que se les impone. Como si ellos supieran que las cosas que hacen siempre tendrán otra versión en un contexto mayor del cual ellos no son ni los actores ni los protagonistas principales. Una tensión entre la versión individual de ellos, y la oficial, las cuales a veces pueden coincidir, aunque es más bien difícil ya que los deja 
como en un mar de dudas, en una tierra de nadie. Porque son personajes que en el fondo sí toman en cuenta esa versión oficial y se sienten oprimidos por ella y muchas veces injustamente tratados. M: ¿Pero son inocentes con respecto a su historia?

$R:$ A veces sí, a veces no, pero son como los dilemas de la acción, que no se sabe exactamente si hicieron esto o si hicieron lo otro, o si ellos llevaron a cabo tal cosa con determinados fines, que después la historia oficial interpreta de modo totalmente diferente y es además una historia oficial cambiante según los contextos, que pueden ser políticos, que pueden ser históricos, propios de una región en la que esos personajes se mueven, o de un país imaginario que habitan.

M: Bueno, hay dos cosas aquí. Yo le hice la pregunta anterior porque quería saber si había alguna ligazón entre ese funcionamiento de precisión y de límite que tiene el personaje con respecto al lenguaje y ese límite que tiene el personaje en relación con el discurso oficial de la historia. Es decir, si habría una ligazón ... porque el cuento arranca con límites, y el personaje también arranca con límites.

$R$ : Yo creo que son personajes un poco náufragos, náugragos en cuanto al sentido de sus vidas. Como que todos apostaron algo a una vida de una significación histórica mayor sobre la cual, al final, se encuentran muy perplejos por estas diferentes interpretaciones que se han dado de ellos. Se encuentran muy perplejos y se refugian en unas certezas cotidianas muy limitadas, que el cuento intenta (quizá es lo que tenga usted en la cabeza) describirlas con cierta precisión, con cierto cuidado, porque son personajes de postrimerías, un poco todos haciendo una especie de largo examen de conciencia, y son personajes que se están preguntando en el fondo ¿quiénes somos? ¿qué hicimos? Y, repito, con la única certidumbre de un universo mínimo que a veces es bastante sórdido, o puede ser solitario o puede ser muy descartado de las cosas "grandes" que suceden.

$M:$ ¿Usted los consideraría personajes trágicos?

$R:$ No, no me atrevería a decir que son personajes trágicos, porque no sé muy bien lo que es un personaje trágico. 
$M:$ Porque hay dos cosas. En primer lugar, parece que es gente que no puede modificar su destino; en segundo lugar, quisiera saber cuál es el grado de responsabilidad que tienen.

$R$ : Bueno, esa es la pregunta que ellos se hacen justamente. No pueden modificar su destino en parte porque son personajes casi todos viejos que reflexionan sobre su vida. No todos, pero algunos. Y la idea es un poco esa, la idea es preguntarse qué carambas le sucedió a sus vidas. Es la pregunta como anterior a la muerte, saber qué demonios pasa, qué demonios va a pasar en este entrecruce entre historia personal e historia grande, entre la versión que ellos han dado de su inserción y la que han dado los historiadores oficiales. Hay, pues, varios elementos en los cuentos: por un lado esa certeza de la vida cotidiana, por otro lado la visión de ellos que es una visión borrosa, angustiada, inquisidora de cuál ha sido su vida $y$, además, la versión oficial, las versiones oficiales, que son una especie como de malla que ellos a la vez desprecian y con la que a la vez quisieran estar en cierta armonía, porque es como si estuvieran convencidos sin decirlo de que ése es el destino escrito.

$M:$ Es decir que la historia oficial es el destino escrito.

$R$ : Es el destino escrito, y se rebelan ante él y dan versiones diferentes y, sin embargo, no llegan a claridades totales. No es que se rebelen claramente y digan eso es una basura, o eso es una falsedad y aquí estoy yo. Ellos saben que no es así, que el cuento de sus vidas es más complejo. El cuento de sus vidas es que ellos también tuvieron que ver con la versión oficial, que ellos tuvieron que ver con el destino grande, que también ellos fueron partícipes de aquello.

M: De manera que la escritura, la construcción, el personaje se escribe, pero toda esa escritura del personaje no puede de ninguna manera modificar la escritura oficial. Son escrituras paralelas.

$R$ : La intención no es que hay una versión sistemáticamente falsa, que es la versión oficial, y la versión verdadera es la que ellos tienen, porque eso sería una simetría muy obvia y además sería una falsedad. Son personajes que tienen que ver, que tuvieron que ver con la historia oficial, o que tuvieron que ver con los hechos a los que se refiere la versión oficial y que quieren como zafarse de eso. 
M: Sin embargo, usted demuestra que los hechos no corresponden a la escritura. Quiero decir, los hechos que desencadenaron la historia oficial no corresponden a la escritura de historia oficial.

$R$ : A ver, elabore la pregunta más claramente.

$M$ : No son personajes totalmente inocentes con respecto a la historia oficial porque participaron en los hechos que la originaron, pero son inocentes frente a la escritura de la historia oficial en relación con los hechos que ellos mismos ocasionaron a veces.

$R$ : A veces. Eso es correcto y esa es justamente una de las tensiones permanentes del cuento o de esos cuentos.

M: Quiérase o no, nos instalamos en la historia con nombre y apellido, y lo que parece, esto es ... no quiero decir una denuncia, porque usted no es ningún escritor de denuncias, de carteles denunciantes, pero sí hay un señalamiento que se le parece mucho. Hay un señalamiento dentro de ese discurrir azaroso de sus personajes, hay un parecido muy nítido con lo que ha sido la tradición histórica de nuestros países de América Latina.

$R$ : Bueno sí, puede haberla. Yo creo que le dije que no me estoy refiriendo a ningún país en concreto, sino que es como una especie de amalgama de varios países, una suerte de país inventado donde hay una serie de recurrencias de la historia hispanoamericana, que quizá usted pueda encontrar en muchos países. Esto es sin duda cierto y a lo mejor expresa esta, no sé como decirlo, esta deriva de destino de los países latinoamericanos, esta especie de capacidad que tenemos de devorar sucesivos planes y sucesivas utopías y sucesivas visiones e ir como tragándolas muy rápidamente: de una pasamos a otra y después volvemos a lo mismo. Y el intento, bueno, no el intento porque yo no escribí bajo esas ideas o con esos propósitos, pero lo que quizá hay en esos cuentos es la recurrencia de este mecanismo, de este mecanismo devorador de planes y de cosas. No se olvide que estos personajes literariamente tienen dos características: una, que son personajes de postrimerías muchos de ellos, y otra que se encuentran como en zonas geográficas que acentúan esta especie de ambigüedad acerca de sus destinos. La geografía debería ayudar en esos cuentos, porque es una geografía de frontera, de límites, es una geografía que tiene en el alma de ella misma una cierta indefinición, indefinición de límites, indefinición de fronteras. Esto está aquí pero podría haber estado allá, esto hoy 
es de aquí pero mañana es de allá. Si usted se fija, están siempre no sólo en las fronteras, sino defendiéndolas, que es casi tanto como decir que defienden la última autonomía de un yo.

M: ¿Qué es lo que delimita la identidad de cada uno de los personajes? Porque están bloqueados por el accionar, están reducidos a su accionar inmediato, su inserción histórica está bloqueada, y geográficamente tampoco pueden ir demasiado lejos.

$R$ : Bueno, es una situación, justamente, usted lo ha dicho bien, es una situación que los convierte en unos personajes que en lugar de llegar a la vejez con sabiduría y lucidez llegan a esa edad envueltos, de nuevo lo repito, en un océano de dudas y en un océano de indefiniciones. Esta es la verdad del asunto.

$Y$ una cosa interesante es que aparentemente estos cuentos son muy diferentes a textos que yo había escrito antes, pero a lo largo de la charla, como que empezó a hilarse una continuidad que me llama la atención, porque también otros cuentos que he escrito, estoy pensando en uno en particular, también tienen este doble juego de la versión individual de unos hechos y una versión canónica que correspondería a la de los historiadores oficiales.

M: ¿Cuál cuento?

$R$ : Pienso en uno que se llama Relatos, que está en el Manual del distraído, que es el que más se prestaría a la comparación; allí es muy claro que hay una versión oficial de una serie de pequeños acontecimientos que ocurrieron, y hay un personaje que va contanto esa historia oficial y al mismo tiempo se da cuenta de la astucia de dicha historia, de sus límites, de los propósitos de esa historia oficial, de sus intenciones y trata de ir desprendiéndose de ella en la medida misma en que la analiza y dice, "Ah carambas, esto lo dice porque quiere enfatizar esto o lo otro, porque le conviene acentuar este aspecto", y él se va como liberando un poco de eso, bueno, no sé si liberando, liberando es una palabra estúpida, se va como dando cuenta del asunto. La fábula de las regiones.

$M$ : Una cosa que quería preguntar antes: ¿usted consideraría a sus personajes como fracasados?

$R$ : No, de ninguna manera, porque si yo los considerara como fracasados entonces estaría asumiendo una visión muy superficial de la vida. ¿Fracasaron por qué?. ¿Porque no ganaron batallas, porque no hicieron esto, porque no hicieron lo otro? No, yo creo 
que eso es muy superficial, yo creo que son personajes que si algo valen se debe a que son bastantes naturales, en el sentido de que esto le pasa a cualquiera, son los problemas de la vida, son los problemas de si les fue bien o les fue mal; creo que estas son preguntas que nos podemos hacer todos, que se puede hacer el hombre que, según alguna medida, tenga mucho éxito. Porque algunos de ellos no son fracasados en ese sentido superficial y pobre de la palabra.

$M$ : Tal vez fracaso no sea la palabra, pero sí queda un sabor en el lector como de pérdida, como de no registro de esa instancia vital que les toca a los personajes, porque iquién registra eso?

$R$ : Bueno, pero esa es una pregunta fundamental en el sentido de preguntar iquién al final de su vida puede decir cómo fue? ¿Quién es el valiente que levanta la mano y dice "yo tengo la versión exacta de lo que fue mi vida"? De alguna manera se juega con esa metáfora en todos los cuentos, de que nadie puede decir con lucidez y con seguridad cómo fue su vida. Ésta es un poco la metáfora o una de las metáforas que persiguen todos los cuentos. Por eso no son fracasados.

$M:$ Sí, desde esa perspectiva no son fracasados.

$R$ : Mire usted, el cuento quiere ser un cuento muy claro, aunque queden estas preguntas no claras, por supuesto. Sin embargo, yo creo que está armado sobre estos dos movimientos del péndulo. Por un lado el destino grande cuestionado, y por el otro la claridad del detalle de la vida cotidiana de ellos, o la importancia de los pequeños objetos de su mundo inmediato.

M: Ahora, hay un privilegio ahí ... Hay un privilegio del detalle de lo íntimo en relación con la historia; la historia oficial aparece siempre como burda, como una cosa burda y gorda, obesa.

$R:$ Sí, así debe ser, la claridad se da en la vida cotidiana y por eso los objetos, que son pocos, tienen que ser muy definidos. Por eso la relación con la geografía es una relación por un lado de amor y, por el otro, como la defensa de un sagrado imperio inocente, que es una especie de gran limbo. La geografía es un mundo sin pecado. Y si no recuerdo mal, cuando intentan justificar ciertos actos defienden la geografía, el mundo natural, algo que para ellos debe ser arcádico. Es quizá el único mundo inocente. Y en ese sentido sí hay una oposición, por burda que parezca, entre geografía e historia. En el 
alma de ellos la geografía es como una zona segura, a pesar de que la geografía historizada es una geografía de frontera; la frontera es como la metáfora de la defensa de ese mundo de limbo, de ese mundo arcádico, de ese mundo inocente que está cercado, cercado por una frontera donde hay bandas, gente levantisca, invasiones.

$M:$ Y el privilegio de los objetos que son pocos y son precisos y funcionan en relación con los personajes, ino es también una prolongación de la identidad de los personajes hacia un costado?

$R$ : Sí, lo entiendo, es lo que decíamos al principio de esta charla, es para ellos un mundo de certeza. Son como personajes un poco acorralados que tienen ese mundo de refugio que son sus casas y también tienen la geografía, siempre hay una relación entre esas casas y la geografía. Ellos descansan en una sensación ancha de la geografía, en saber que hay como un poder que no es histórico, que es un poder no político que los rodea y que los acoge y que es muy anterior a ellos. Por eso hay muchas referencias a los grandes ríos, a los silencios, a una sensación de extensión.

M: Es cierto lo que dice, porque además ese silencio es grande. Lo mínimo se vuelve grande a nivel geográfico, pero en ese sentido es cierto, la geografía sustituye a la historia.

$R$ : Sustituye en ese sentido, como un refugio.

$M$ : Volviendo a la palabra tono con que usted habla de los personajes. Cuando usted se remite a la historia oficial, dice, es una historia burda, con un solo sentido ...

$R:$ No, con un solo sentido no, uno de los dramas de esa historia oficial es que es tan cambiante, que no da versiones fijas, que a lo mejor cuando el personaje tenía treinta años, él para la historia oficial era determinada cosa, y a los cincuenta años es otra. Según los cambios y las versiones políticas de ese centro simbólico lejano que es el productor de la historia, se va alterando continuamente. Esta es la angustia de ellos.

M: ¿Entonces no es una historia de una sola dimensión? ¿No es algo que señale una única cosa?

$R$ : No, yo diría que hay precisamente la variedad de la versión oficial que es una de las cosas enloquecedoras para ellos.

M: Me queda claro. 
$R$ : Esa es una de las cosas que forma parte de nuevo de esa metáfora de quienes somos, que es cambiante, que obedece a otras señales, que obedece a otros intereses, que escapa al control de ellos, que poco o nada tiene que ver con las categorías de verdad o no verdad, sino que se mueve con categorías de intereses. Muchas veces ellos lo reconocen y dicen: "los historiadores tienen que ordenar la patria, tienen que dar alguna versión de este caos". Y a la vez está la angustia terrible de que les va cambiando el espejo continuamente. Es como un señor que ahora es un héroe y mañana es un traidor.

$M$ : Cuando usted se refiere a esa historia de cualquier manera, usted la define con un trazo demasiado rápido a mi manera de escuchar, y cuando habla de los perosnajes y cuando habla del entorno de los personajes, habla con cierta actitud como piadosa. Me parece evidente, aunque usted quiera mantener la imparcialidad, que usted está tomando posición.

$R$ : De alguna manera sí, claro, yo estoy tomando posición, porque tomar posición, adviértalo bien, no es tomar posición política o ante los hechos que en ese cuento determinado llevaron a cabo los personajes, sino que es tomar posición frente a la metáfora. Yo me hago cargo de la mtáfora, y eso significa que yo estoy del lado de ellos en el sentido de decir que es un lío saber quienes somos, en este preciso sentido yo estoy del lado de ellos. Estoy del lado de ellos en cuanto a decir, por ejemplo, no, en la batalla tal la razón la tuviste tú y no la versión oficial que dice que fuiste un miserable o que fuiste un cobarde o que fuiste un traidor o que fuiste un imbécil. No, no se trata de eso, de ninguna manera. Se trata de tomar partido por una visión más profunda de la vida, se trata de tomar partido por la pregunta esencial que nos hacemos. Se trata de tomar partido por una interpretación. Y yo creo que la justicia hacia esos personajes es precisamente tomarlos en serio, y tomarlos en serio de ese modo, no dándoles la razón frente a determinados hechos históricos en los que ellos fueron protagonistas.

M: Y es una manera de escapar de esa relación dialéctica negativa que se mantiene entre los dos planos. Porque si usted se sitúa en la metáfora, está escapando a la vez del discurso oficial y está escapando también del discurso de la vida concreta ... 
$R:$ De la vida concreta de ellos en cuanto a hechos históricos, yo no estoy tomando partido con ellos.

$M:$ Sí, está situado en un tercer lugar ...

$R$ : Sí, yo no le estoy diciendo tú eres un traidor o tú eres un héroe, sino que yo estoy con ellos en sus preguntas y en sus angustias fundamentales acerca del destino de ellos. De ese lado sí estoy yo.

M: Claro, ése es otro plano de lo que estábamos hablando, es otro lugar. Ese sí sería un grado de dominio del narrador, de control, ese sí es un grado de control.

$R$ : Probablemente, pero es la única lógica posible que pueden tener esos cuentos. Si no, no tendrían sentido, si no, yo sería como un pequeño historiador que quiere rectificar hechos históricos. Yo no soy eso, yo no estoy rectificando hechos históricos.

M: O de cambiar la historia oficial por la historia cotidiana.

$R:$ O por la historia cotidiana. No pretendo contar la verdadera historia, como si yo hubiese estado del otro lado de la batalla. Yo no estoy en eso. Porque yo asumo como inevitable que exista esa versión oficial de la historia. Yo no lo veo como un acontecimiento trivial o baladí que ocurrió en unas circunstancias determinadas o en una región específica. Sino que la considero como una metáfora. La acepto como algo de lo que nadie se escapa. No como una circunstancia pasajera de una determinada región en un determinado año de la historia.

M: Sí, porque si no, además ese afán de corrección lo convertiría a usted en un nuevo escritor oficial, del lado de las cosas.

$R$ : Del otro lado de las cosas. No se trata de eso. Se trata de decir ( $y$ uno se avergüenza un poco de pronunciar estas palabras), como éstos son los elementos que componen la vida y no una pequeña anécdota. Y la historia oficial en estos casos es un supuesto colegio de historiadores. Así es aquí, pero en otros cuentos puede ser otra cosa. Como le decía, en aquel otro cuento se trata la "versión canónica" de un relato, o la versión establecida.

$M$ : Logramos identificarlo a usted dentro del texto. Ahora me cambia un poco la perspectiva de los personajes en el sentido de que veo que no lo necesitan a usted como narrador. Acá se desprenden 
los personajes del resto del cuento, en este momento para mí, porque yo pensé que usted estaba en cierta forma encadenado a los personajes y veo que no es así.

$R$ : No, no es así. Yo los puedo querer, pero yo no soy la voz reivindicadora que ellos esperaban. Yo no soy de los que van a escribir la historia verdadera.

$M$ : Esto quedó claro. Porque yo no estoy diciendo tampoco que la historia oficial es necesariamente mentirosa. Es cierto. Mirado desde esa otra perspectiva cambia totalmente. Se logra un gran nivel de ambigüedad del narrador, porque ¿cómo discernir aquí cuál es el punto de vista del narrador? No se sabe. Es también como preguntarse cuál es el punto de vista de uno como ser humano viviendo en esta historia. ¿Cómo puede uno tener un punto de vista?

$R$ : Se puede tomar posición frente a la metáfora, y yo creo que la invitación subterránea al lector es ésa: "Entiende la metáfora." Pongámoslo de una manera más simple: supongamos que yo narrara hechos que, en efecto, fueron históricos en el sentido claro de la palabra y dijera que la versión oficial dice tales y cuales cosas de estos hechos históricos (una batalla a lo mejor real) y estos otros dicen otras cosas o no saben muy bien, porque cambian las interpretaciones oficiales. Si fuera asi y me viera usted como quien dice: "No, no, yo voy a dar la verdadera historia de cómo sucedió el asunto. Los historiadores oficiales exageraron aquí, etc., o tuvieron tales motivaciones para decir esto o aquello, el personaje tiene razón, en realidad hizo tal cosa y lo hizo bajo tales motivos, etc.", entonces yo estaría ajustando la historia oficial, y me convertiría en un historiador. Esto de ninguna manera es el sentido y por eso trato de que los hechos históricos $-\mathrm{y}$ creo que deben funcionar técnicamente así-, tengan una cierta lejanía, una cierta cosa difusa. Si yo precisara demasiado esos hechos se daría la impresión de yo soy un gran rectificador de la historia. O si yo los ejemplificara con cosas reales que ocurrieron en la historia, con nombres reales de generales o de batallas, de levantamientos o de revoluciones políticas. Yo no quiero eso.

M: Ahora me está pareciendo que lo que usted está tratando de demostrar es justamente que la vida es no narrable, siempre partiendo de la base de esa tercera posición, de la metáfora como la llama usted. Usted no es un rectificador porque sabe que si se mete a 
corrector va a crear una nueva historia oficial. Da la impresión de que los discursos no pueden coexistir, uno trata de sustituir al otro siempre y lo que hoy es marginal, mañana puede ser oficial y así vamos. Pero esa tercera posición es como decir esto no se puede narrar.

$R$ : Hay una especie de enloquecimiento de las interpretaciones y ahí, en esos filones, en esos resquicios vive la gente.

$M:$ Por eso usted decía antes que el efecto de realidad se causaba proponiendo varias historias sin continuación, como una especie de rizomas que salen para todos lados...

$R:$ Sí, historias paralelas que no se continúan. Alusiones que no se continúan. Pero esos son ya más trucos literarios ...

$M:$ Sí, pero corresponden al nivel del lenguaje.

$R$ : Sí, es decir, alusiones a un personaje, alusiones a una historia, alusiones a una anécdota, cuentos apenas empezados dentro del cuento, que no se continúan y que van creando como afluentes al río central. Yo creo que los grandes cuentos siempre tienen eso, porque eso es lo que genera mundo en el lector.

$M$ : Claro, genera mundo además en la vida cotidiana. Usted cuando vive, lo hace con la certeza de que están ocurriendo muchas cosas que usted podía haber seguido y no siguió, uno vive con eso.

$R$ : Es el realismo de las bifurcaciones. Cuando siento una realidad muy bifurcada, narrada muy bifurcadamente aunque tenga su centro, entonces es cuando siento el sabor de la realidad.

$M$ : Es verdad, y cuando usted elige, porque se supone que usted elige una de las historias posibles, esa historia no es tan fatalmente contundente que niegue las ausentes.

$R:$ No, las va arrastrando y uno dice, caramba, esta historia que me está contando, en definitiva es una historia, pero con cuántas adherencias, con cuántas posibilidades de irse por otro lado, de alterarse, de cambiar de signo, etc. Yo creo que así es la realidad. Yo vería así el asunto: quiero que todo este tipo de cuentos tengan ciertos elementos constantes, por ejemplo esto de los historiadores, por ejemplo estas tensiones, por ejemplo esta región, por ejemplo un pasado histórico difuso, etc. Bueno, yo quiero que tenga todo eso. Uno siempre quiere publicar muy rápido, pero yo debería esperar idealmente a que fueran por lo menos siete cuentos para que ese elemento que usted señalaba de un mundo coherente, de un mundo 
reglado apareciera como uno de los protagonistas fuertes del libro entero. Y entonces que fuera un libro, que fuera, sí, un libro de cuentos, pero que a la vez fuera un libro de cuentos muy unidos todos en un solo universo y, por consiguiente, que se asemejara a una novela. Que tuviera intercomunicación entre los personajes. Ya hay algunas, en la repetición de ciertos nombres, en las alusiones a ciertas cosas.

$M:$ Como seguir varias afluencias del río.

$R$ : Bueno, sí, volvemos a la metáfora de la bifurcación, o mejor dicho a la metáfora de un delta, y entonces lo que no se nota en un solo cuento, se va a notar en el libro, que es el universo completo, o un mundo muy completo, un mundo en el que se mueven todos estos cuentos, el cual saldrá como un personaje a la vez dependiente e independiente de los cuentos. Esto es el asunto.

$M: ~ ¿ Y$ ya tiene algunos?

$R$ : Bueno, le decía que había terminado uno y éste sería el quinto. $Y$ tengo medio pensado otro. Otro que considera un aspecto distinto, que se fija en uno de esos elementos que componen ese universo y que antes no era temático, que es el mundo de los historiadores, de los historiadores oficiales.

$M$ : Pero cómo, el mundo cómo, ila vida?

$R$ : No, sería un cuento sobre los historiadores oficiales o en relación con ellos, no lo sé muy bien todavía en el detalle, pero sé que se trata de ellos. Y después me gustaría llegar a siete para que tuviera más peso, más sustancia. A mí atravesar la raya de las cien páginas me parece un milagro fantástico. Yo soy un esclavo de los formadores y los linotipistas, que son los que a veces me hacen cruzar, de contrabando, la raya de las cien páginas. A fuerza de mañas tipográficas. Pero quisiera que esta vez yo pudiera cruzar la raya sin tantas mañas tipográficas, que la pudiera atravesar solo, sin la ayuda de los formadores, diseñadores, linotipistas, o máquinas, puesto que casi no quedan linotipistas. Bueno, qué le parece, ilo dejamos hasta aquí, o tiene usted alguna otra pregunta?

$M$ : Usted hablaba del tiempo como lo único que importaba.

$R$ : No sé si usted tiene en la cabeza algo así como decir que hay ... mire, sin usar la palabra tiempo, usando otra palabra, que siempre hay dos velocidades en los cuentos éstos. Está la velocidad del mundo circundante, y está la velocidad del mundo histórico grande. 
Bueno, también se puede ver eso como dos tiempos. El tiempo de la historia, no oficial, sino la historia grande y la historia de las vidas en el momento de la narración, vidas que a veces son muy lentas.

$M:$ Sí, son evidentemente más lentas que las otras.

$R$ : Mucho más.

$M$ : Podría ser por ahí que usted dijo que el tiempo era lo importante ...

$R$ : Y claro, estas velocidades y estos tiempos son la materia misma de la narración. Esto es indudable.

M: Parecen un tiempo menor. Esa especie de "literatura menor" que se cree que es la de la vida cotidiana. Parecen como espacios incrustados en el tiempo mayor, porque al reloj lo diseña la historia, la historia oficial.

$R$ : Bueno, a uno de los relojes lo diseña la historia, pero yo sí quiero que haya contraste entre las dos velocidades $y$, por consiguiente, entre los dos tiempos, porque esto es fundamental para la comprensión de lo que llamábamos la metáfora. Es fundamental este tiempo vivido de ellos, lento, que es el que permite todas las perplejidades y ese tiempo veloz que es el universo de las interpretaciones, que es el universo cambiante ... que es el sentir inaferrable de las vidas.

$M:$ Sí, no hay ninguna paranoia porque no hay ninguna búsqueda de la verdad.

$R$ : No, en el sentido de saber cuáles fueron los hechos. Bueno, ellos dan su versión, que es una versión siempre como rabiosa porque no coincide con la otra, o porque la otra los ha traicionado. Ellos se sienten muy manipulados por la otra. No tanto manipulados, manipulados no es la palabra quizá, se sienten angustiados frente a la otra. Angustiados porque es como sí dijeran "iy qué tal si la otra también tiene algo de razón?"

$M$ : Lo que sí parece es que ninguna sobrevive sin la otra.

$R$ : Así es, ellos están hechos de las dos y la idea es ésa. La verdadera pregunta es, si éstos son los elementos, ies posible que haya una interpretación de la vida de una persona? Y no la pregunta ¿cuál es la interpretación en este caso en particular? Porque en algunos de esos relatos, el lector debe darse cuenta de que muchas de esas cosas que el personaje rechaza como interpretación pueden ser verdaderas. Entonces yo creo que esa es la fórmula mejor para 
decirlo: dados estos elementos y dados estos juegos, ies posible dar con una verdadera interpretación? Al revés de una novela policíaca que busca cuál es la verdadera interpretación ...

$M$ : De buscar al asesino.

$R$ : De buscar al asesino. No es ése el camino, porque eso me convertiría a mí de nuevo en un tercer historiador, el verdadero. Puede tener a veces la apariencia como de una búsqueda casi policíaca de lo que pasó, de lo que no pasó, qué sucedió realmente respecto a un tema, pero la metáfora general es que es muy difícil dar con una interpretación y que son las preguntas eternas que nos vamos a seguir haciendo y que no es una falta de datos, no es una ausencia de elementos, sino que hay algo más esencial que nos va siempre a empujar a este tipo de preguntas y a este tipo de cuestionamientos. 